Abbreviated Key Title: Sch J Med Case Rep

ISSN 2347-9507 (Print) | ISSN 2347-6559 (Online)

Journal homepage: https://saspublishers.com

\title{
Atypical Case of Conjunctival Epitheloid Hémangioma
}

Yassine El Ghani $^{1 *}$, Sarah Belghmaidi ${ }^{1}$, Bouda Raja ${ }^{1}$, Hajji Ibtissam ${ }^{1}$, Abdeljalil Moutaouakil ${ }^{1}$, Aarab Ayoub ${ }^{2}$, Hanane Raiss ${ }^{2}$

${ }^{1}$ Ophthalmology Department at the Mohamed VI University Hospital Center in Marrakech, Morocco

${ }^{2}$ Anatomopathology Department at the Mohamed VI University Hospital Center in Marrakech, Morocco

DOI: $10.36347 /$ simcr.2021.v09i03.005

| Received: 18.01.2021 | Accepted: 02.02.2021 | Published: 08.03.2021

*Corresponding author: Yassine El Ghani

\section{Abstract}

Conjunctival capillary hemangioma is an uncommon vascular tumor, we present a unique and atypical case spontaneously developed in an adolecent with allergic conjunctivitis, without associated systemic disease process or cutaneous manifestations.

Keywords: Hemangioma, ocular surface, vascular tumors, conjunctiva.

Copyright $($ C) 2021 The Author(s): This is an open-access article distributed under the terms of the Creative Commons Attribution 4.0 International License (CC BY-NC 4.0) which permits unrestricted use, distribution, and reproduction in any medium for non-commercial use provided the original author and source are credited.

\section{INTRODUCTION}

among the rarest conjunctiva tumors we find the vascular tumors, including the capillary hemangioma which is even rarer than the others [6]. Here, we discuss development of a conjunctival hemangioma in a 15 year old patient with seasonal allergic conjunctivitis.

\section{CASE Représentation}

This is a 15-year-old adolescent, followed for seasonal allergic conjunctivitis 3 years ago, treated by local anti histamine with good évolution, currently consults for an evolutive conjunctival lésion of left eye since 7 months, the clinical examination finds a visual acuity at 10/10 th, a conjunctival lésion of pinkish color with sentinel vessels and melanic pigmentations of brown color at the bottom and surrounding the lesion associated with a corneal invasion on $2 \mathrm{~mm}$ of temporal side (Figure-1); the lens was transparent and the fundus was normal.

An excisional biopsy with conjunctival autograft (Figure-2) was done, the anatomopathological exam objectified an epithelioid hemangioma (Figure 3 $\& 4$ ), with no sign of atypical mitosis, tumor necrosis or sign of malignancy; the post-op follow-up were normal, a local corticosteroid therapy was prescribed with good évolution.

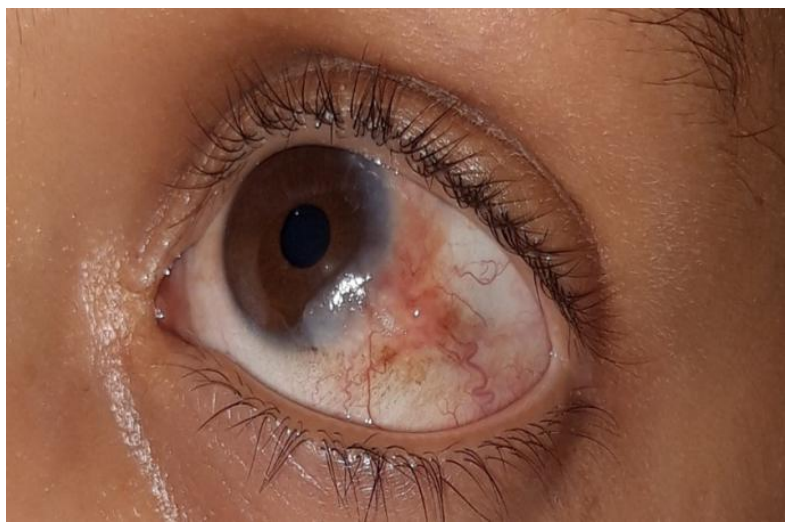

Fig-1

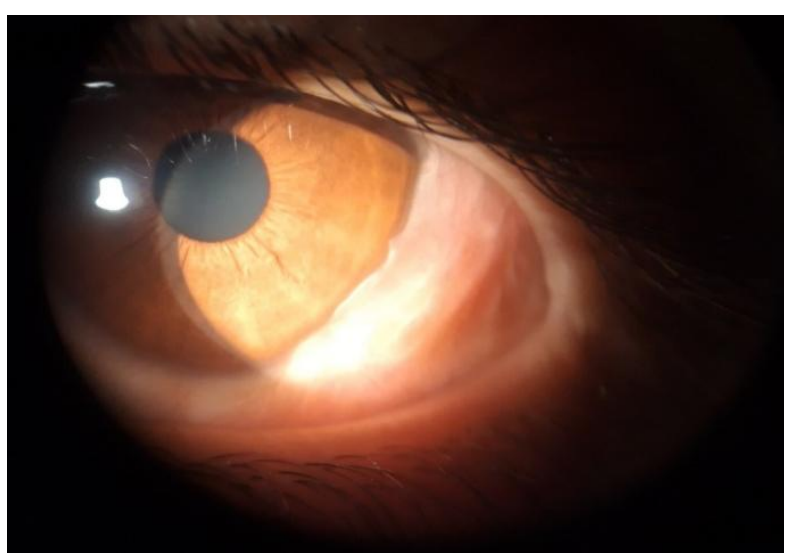

Fig-2 


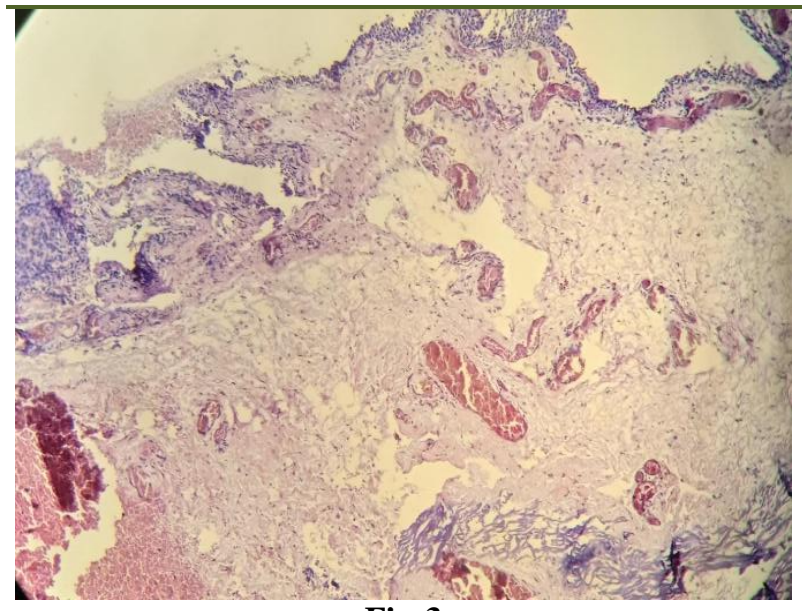

Fig-3

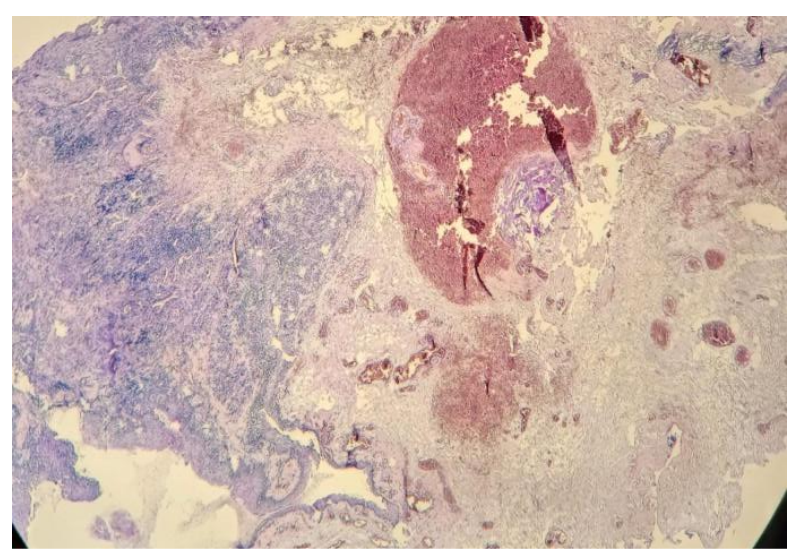

Fig-4

\section{DISCUSSION}

The conjunctiva is a membrane with a surface composed of non keratinizing stratified squamous epithelium intermixed with goblet and Langerhans cells [1]. Beneath conjunctival epithelium lies the conjunctival substantia propria, which is composed of a thin layer of loose connective tissue [1].

Tumors of the conjunctiva comprise a large and varied spectrum. These tumors are grouped into congenital and acquired lesions depend the histologic origine we can subdivised this tumors on epithelial, melanocytic, vascular, fibrous, neural, histiocytic, myxoid, myogenic, lipomatous, lymphoid, leukemic, metastatic and secondary tumors [2].

Conjunctival capillary hemangioma is a tumor derived from endothelial cells [3] it's mainly a benign lésion, asymptomatic and mostly congenital in origin, its progression or de novo growth is rare in adulthood
Yassine El Ghani et al., Sch J Med Case Rep, Mar, 2021; 9(3): 214-215 [4]. These tumors may be isolated or associated with other ocular capillary hemangiomas (e.g. Sturge Weber Syndrome) [5], our case are atypic because of the clinical aspect with the melanic pigmentation contrasting with the typical pinkish appearance and his association with allergic conjunctivitis which is often responsible for chronic inflammation of the ocular surface and which suggests the cause and effect relationship, which must be confirmed with others observation.

If in our case an excisional biopsy with conjunctival autograft was performed in addition to the local corticosteroid therapy, other authors discuss differents therapeutic means such as cryotherapy, chemo / radiotherapy, timolol eye dops and which can even include mutilating gestures (enuleation, exenteration,) in the most advanced cases [6].

\section{CONCLUSION}

All tumors of the conjunctiva specially the hemangioma needs to manage each case individually and observe for unusual characteristics and growth pattern. Our case is atypical clinical presentation and was associated to the seasonal allergic conjunctivitis without any associated systemic or cutaneous manifestations.

\section{REFERENCES}

1. Yanoff M, Fine BS. Conjunctiva. In: Yanoff M, Fine BS, editors. Ocular pathology. St. Louis, MO: 5. Mosby, 2002; 215-40.

2. Shields CL, Shields JA. Conjunctival tumors in children. Current opinion in ophthalmology. 2007 Sep 1;18(5):351-60.

3. Muranaka K, Kunimatsu S, Kaji Y, Joko S, Kato S, Numaga J. Conjunctival haemangioma in an elderly patient. Eye. 1999 Nov;13(6):790.

4. Fernández-Vega CL, Tresserra F, de la Paz MF. De novo growth of a capillary hemangioma of the conjunctiva. Archivos de la Sociedad Espanola de Oftalmologia. 2014 Mar;89(3):127-129.

5. Shields JA, Mashayekhi A, Kligman BE, Kunz WB, Criss J, Eagle Jr RC, Shields CL. Vascular tumors of the conjunctiva in 140 cases. Ophthalmology. 2011 Sep 1;118(9):1747-53.

6. Alanna N, Perry HD, Rosenberg ED, Rubina C. Conjunctival Capillary Hemangioma. Cureus. 2017;9(11). 